\title{
Leptin promotes the growth of breast cancer by upregulating the Wnt/ $\beta$-catenin pathway
}

\author{
XI LIANG ${ }^{1}$, SHUJUN WANG $^{1}$, XUEJU WANG ${ }^{2}$, LIJUAN ZHANG $^{2}$, HAIDONG ZHAO $^{1}$ and LE ZHANG ${ }^{2}$ \\ ${ }^{1}$ Department of Breast Surgery, The Second Affiliated Hospital of Dalian Medical University, Dalian, Liaoning 116023; \\ ${ }^{2}$ Department of Breast Surgery, China-Japan Union Hospital, Jilin University, Changchun, Jilin 130033, P.R. China
}

Received December 5, 2017; Accepted April 13, 2018

DOI: $10.3892 /$ etm.2018.6212

\begin{abstract}
The present study aimed to investigate the role of leptin in the growth of breast cancer. In the present study, expression of leptin in tumor tissues and adjacent tissues was detected by reverse transcription-quantitative polymerase chain reaction. Serum leptin in patients with breast cancer and normal healthy controls was detected by ELISA. Different concentrations of leptin were used to treat breast cancer cells, and cell proliferation was detected by cell proliferation assay. Interactions between leptin and Wnt/ $\beta$-catenin were evaluated by western blotting. It was demonstrated that expression of leptin mRNA was significantly higher in tumor tissues than in adjacent tissues in 43 out of 48 patients. Serum level of leptin was significantly higher in patients with breast cancer than in normal controls. Leptin promoted the proliferation of breast cancer cells in a dose-dependent manner. Leptin significantly increased the expression level of $\beta$-catenin in breast cancer cells. Treatment with Wnt inhibitor reduced the enhancing effects of leptin on proliferation of breast cancer cells. The results of the present study therefore indicate that leptin may promote the growth of breast cancer by upregulating the $\mathrm{Wnt} / \beta$-catenin pathway.
\end{abstract}

\section{Introduction}

Breast cancer is a type of malignancy that originates in breast tissue (1). As one of the most prevalent types of cancer in females, breast cancer affects 1 in 8 females during their lives, and is associated with notable psychological and economic burdens to patients and their families $(2,3)$. Treatment outcomes for the majority of patients with breast cancer with initial cytotoxic drug treatments, including methotrexate, are typically poor due to intrinsic resistance (4). In addition, the long-term use of certain drugs, including cyclophosphamide,

Correspondence to: Dr Le Zhang, Department of Breast Surgery, China-Japan Union Hospital, Jilin University, 126 Xiantaida Street, Changchun, Jilin 130033, P.R. China

E-mail: digf4wcu@yeah.net

Key words: leptin, breast cancer, proliferation, Wnt/ $\beta$-catenin will lead to the development of drug resistance, thereby inducing the development of aggressive malignancies $(5,6)$. Therefore, the development of novel treatment targets is urgently required to improve the treatment outcomes of breast cancer.

Leptin is a hormone that is primarily secreted by adipose cells, which have important roles in regulating energy balance by inhibiting hunger (7). Recent studies have demonstrated that upregulated expression level of leptin gene is also correlated with the development of various human diseases, such as cardiovascular disease (8), non-alcoholic fatty liver disease (9) and different types of cancers (10). The functionality of leptin in the tumor microenvironment of breast cancer has been well studied: It has been demonstrated that leptin induces obesity and contributes to the development of this disease (11). Effects of leptin on breast cell proliferation remain to be elucidated. The current study aimed to investigate the role of leptin in the growth of breast cancer.

\section{Materials and methods}

Patients. A total of 48 female patients with breast cancer were recruited from China-Japan Union Hospital (Changchun, China) from July 2015-January 2017. Patients were aged from 31.0-68.0 years, with a mean age of $48.3 \pm 7.6$ years. All patients received surgical resections, and tumor tissues and adjacent healthy tissues were collected during surgery. At the same time, a total of 37 healthy participants were also selected to serve as a control group. Age of controls ranged from 29.0-66.0 years, with a mean age of $46.4 \pm 9.1$ years. No significant difference in age was observed between the patient and control groups. The present study was approved by the Ethics Committee of China-Japan Union Hospital, and all patients provided written informed consent.

Preparation of serum samples. Fasting blood $(20 \mathrm{ml})$ was extracted from all patients and controls. Blood was stored at room temperature for $1 \mathrm{~h}$, followed by centrifugation at $1,000 \mathrm{x} \mathrm{g}$ for $15 \mathrm{~min}$ at room temperature to collect serum. Serum samples were stored at $-80^{\circ} \mathrm{C}$ prior to further use.

ELISA. Serum leptin was detected using an ELISA kit (cat. no. KAC2281; Thermo Fisher Scientific, Inc., Waltham, MA, USA). All operations were performed in strict 
accordance with the manufacturer's protocol. Serum leptin was normalized to $\mathrm{ng} / \mathrm{ml}$.

Cell lines and cell culture. The normal human breast cell line Hs 578Bst, and the breast cancer cell lines MCF-7 and MDA-MB-231 were purchased from American Type Culture Collection (ATCC; Manassas, VA, USA). Hs 578Bst cells were cultured with ATCC Hybri-Care medium (cat no. 46-X) containing $1.5 \mathrm{~g} / 1$ sodium bicarbonate, $30 \mathrm{ng} / \mathrm{ml}$ mouse epidermal growth factor (Sigma-Aldrich; Merck KGaA, Darmstadt, Germany) and $10 \%$ fetal bovine serum (Sigma-Aldrich; Merck KGaA). MCF-7 cells were cultured with ATCC-formulated Eagle's minimum essential medium (cat no. 30-2003) containing $0.01 \mathrm{mg} / \mathrm{ml}$ human recombinant insulin (Sigma-Aldrich; Merck KGaA) and 10\% fetal bovine serum (Sigma-Aldrich; Merck KGaA). MDA-MB-231 cells were cultured with ATCC-formulated Leibovitz's L-15 medium (cat no. 30-2008) containing 10\% fetal bovine serum (Sigma-Aldrich; Merck KGaA). Cells were cultured at $37^{\circ} \mathrm{C}$, and harvested during logarithmic growth phase for subsequent experiments.

Cell proliferation assay. Cells from each cell line were transferred into 96-well plates containing the corresponding aforementioned medium with $5 \times 10^{3}$ cells per well. Following incubation at $37^{\circ} \mathrm{C}$ for $3-5 \mathrm{~h}$, cell adhesion was reached and $100 \mu 1$ Dulbecco's modified Eagle's medium (Sigma-Aldrich; Merck KGaA) was added. Cells were cultured at $37^{\circ} \mathrm{C}$ with the different concentrations of leptin $(0,25,50$ and $100 \mathrm{mM}$; Sigma-Aldrich; Merck KGaA), and $10 \mu 1$ cell counting kit- 8 solution (Sigma-Aldrich; Merck KGaA) was added at 24, 4872 and $96 \mathrm{~h}$ later. Following incubation for another $4 \mathrm{~h}$, optical density values at $450 \mathrm{~nm}$ were measured using a microplate reader. For Wnt inhibitor PNU-74654 $(20 \mu \mathrm{M}$; Sigma-Aldrich; Merck KGaA) treatment, $20 \mu \mathrm{M}$ PNU-74654 and $100 \mathrm{mM}$ leptin was added to the culture medium under the same conditions as aforementioned.

Reverse transcription-quantitative polymerase chain reaction $(R T-q P C R)$. Total RNA was extracted from tumor tissues, adjacent healthy tissue, serum and in vitro cultured cells using TRIzol reagent (Thermo Fisher Scientific, Inc.), and cDNA was synthesized via reverse transcription using Oligo(dT)15 primer (Shanghai Sangong Pharmaceutical Co., Ltd., Shanghai, China), dNTPs (Sigma-Aldrich; Merck KGaA) and Avian Myeloblastosis Virus reverse transcriptase (New England BioLabs, Inc., Ipswich, MA, USA) and its buffer (New England BioLabs, Inc.). The temperature protocol for reverse transcription was: $25^{\circ} \mathrm{C}$ for $5 \mathrm{~min}, 55^{\circ} \mathrm{C}$ for $20 \mathrm{~min}$ and $75^{\circ} \mathrm{C}$ for $15 \mathrm{~min}$. The following primers were used in qPCR: Leptin, forward 5'-CAAGCAGTGCCTATCCAGA-3' and reverse 5'-AAGCCCAGGAATGAAGTCCA-3'; and GAPDH forward 5'-GAGTCAACGGATTTGGTCGT-3' and reverse 5'-TTG ATTTTGGAGGGATCTCG-3'. A $25 \mu 1$ reaction mixture was prepared using SYBR ${ }^{\mathrm{TM}}$ Green Master Mix (Thermo Fisher Scientific, Inc.) according to manufacturer's protocol and the reaction conditions were as follows: $94^{\circ} \mathrm{C}$ for $3 \mathrm{~min}$, followed by 40 cycles of $94^{\circ} \mathrm{C}$ for $10 \mathrm{sec}, 55^{\circ} \mathrm{C}$ for $30 \mathrm{sec}$ and $72^{\circ} \mathrm{C}$ for $25 \mathrm{sec}$, and $72^{\circ} \mathrm{C}$ for $10 \mathrm{~min}$. PCR products were subjected to agarose gel electrophoresis and results were observed using the ChemiDoc ${ }^{\mathrm{TM}}$ and GelDoc ${ }^{\mathrm{TM}}$ imaging system (Bio-Rad Laboratories, Inc., Hercules, CA USA). Quantity One ${ }^{\circledR} 1-D$ Analysis Software V4.6.7 (Bio-Rad Laboratories, Inc.) was used to analyze the results with GAPDH endogenous control using $2^{-\Delta \Delta \mathrm{Cq}}$ method (12).

Western blotting. Cells of the MG-63 and MDA-MB-231 cell line were treated with 0 (control cells; C) or $100 \mathrm{mN}$ leptin (leptin group). Cell lysis buffer (cat. no. P0013K; Beyotime Institute of Biotechnology, Haimen, China) was then used to extract total protein from these cells. Total protein concentration was determined via bicinchoninic acid assay. A total of $20 \mu \mathrm{g}$ protein from each sample was subjected to electrophoresis using 10\% SDS-PAGE, and were subsequently transferred to a polyvinylidene difluoride membrane (Bio-Rad Laboratories, Inc.). Blocking was performed by incubating membranes with $5 \%$ skimmed milk at room temperature for $2 \mathrm{~h}$. Following washing, membranes were incubated with primary antibodies against $\beta$-catenin (1:1,200; cat. no. ab16051; Abcam, Cambridge, UK) and endogenous control $\beta$-actin $(1: 1,000$; cat. no. SAB5500001; Sigma-Aldrich; Merck KGaA) overnight at $4^{\circ} \mathrm{C}$. Following washing, membranes were incubated with horseradish peroxidase conjugated anti-rabbit immunoglobulin G secondary antibodies (1:1,000; cat. no. MBS435036; MyBioSource, San Diego, CA, USA) at $37^{\circ} \mathrm{C}$ for $1 \mathrm{~h}$. Enhanced chemiluminescence (SuperSignal; Thermo Fisher Scientific, Inc.) was performed to detect the signals and Quantity One ${ }^{\circledR}$ 1-D Analysis Software V. 4.6.7 (Bio-Rad Laboratories, Inc.) was used to measure grayscale. This experiment was repeated three times.

Statistical analysis. Data were analyzed using SPSS 19.0 (IBM, Corp., Armonk, NY, USA). Comparisons between two groups were performed using Student's t-test and comparisons among multiple groups were performed using one-way analysis of variance followed by a post-hoc LSD test. $\mathrm{P}<0.05$ was considered to indicate a statistically significant difference.

\section{Results}

Expression of leptin mRNA in tumor tissues and adjacent healthy tissues of patients with breast cancer. Expression of leptin is upregulated in different human diseases, including cardiovascular diseases (8) and non-alcoholic fatty liver disease (9). Therefore, expression of leptin mRNA in tumor tissues and adjacent healthy tissues was detected via RT-qPCR. As presented in Fig. 1, expression of leptin mRNA was significantly higher in tumor tissues than in adjacent healthy tissues in 43 of 48 patients with breast cancer $(\mathrm{P}<0.01$. This suggests that increased expression level of leptin is associated with the development of breast cancer.

Serum leptin in patients with breast cancer and healthy controls. Serum leptin was detected by ELISA. Results indicated that levels of serum leptin were significantly higher in patients with breast cancer than in healthy controls $(\mathrm{P}<0.05$; Fig. 2).

Leptin treatment promoted breast cancer cell proliferation. As presented in Fig. 3A, expression level of leptin mRNA 


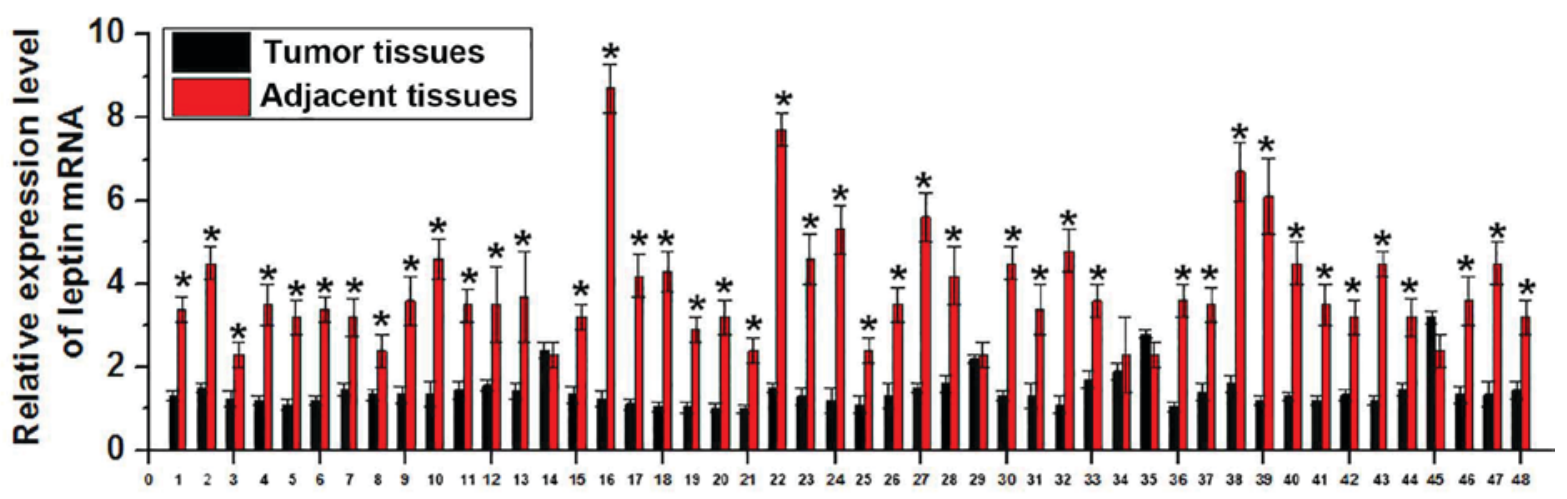

Patients with breast cancer $(n=48)$

Figure 1. Expression of leptin mRNA in tumor tissues and adjacent healthy tissues of 48 patients with breast cancer. ${ }^{*} \mathrm{P}<0.01$ vs. adjacent healthy tissues.

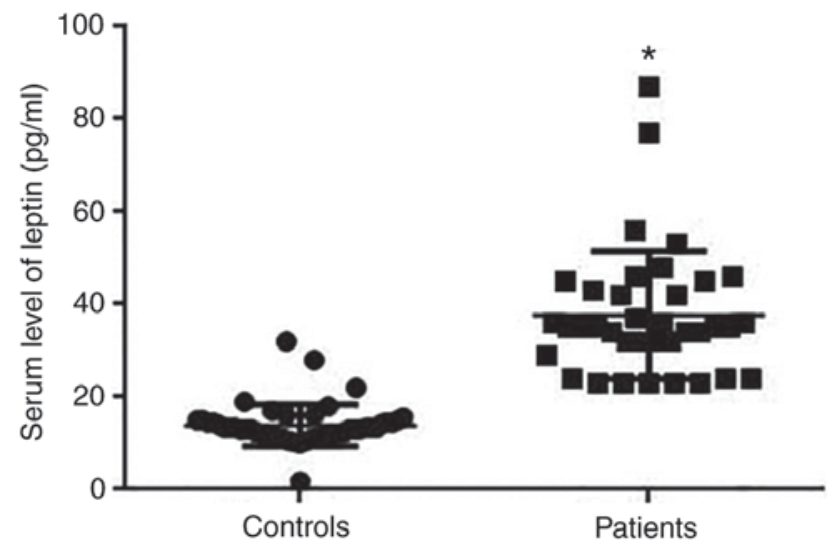

Figure 2. Serum level of leptin protein in patients with breast cancer and normal controls. ${ }^{*} \mathrm{P}<0.05$ vs. controls.

was significantly lower in the normal human breast cell line Hs 578Bst than in the breast cancer cell lines MCF-7 and MDA-MB-231 $(\mathrm{P}<0.05)$. Different concentrations of leptin were used to treat breast cancer cells and effects of leptin on cell proliferation were detected via cell proliferation assay. As presented in Fig. 3, the cell proliferation ability of the MCF-7 (Fig. 3B) and MDA-MB-231 (Fig. 3C) cell lines were markedly increased by leptin treatment in a dose-dependent manner. However, leptin treatment had no marked effect on the cell proliferation ability of the normal human breast cell line Hs 578Bst (data not shown).

Leptin treatment increased expression level of $\beta$-catenin in breast cancer cells. The Wnt/ $\beta$-catenin pathway serves pivotal roles in the development of different types of cancer, including ovarian (13) and colorectal cancer (14). Therefore, the effects of leptin on the Wnt $/ \beta$-catenin pathway were detected by western blotting. As presented in Fig. 4, the expression level of $\beta$-catenin was significantly increased in both breast cancer cell lines following $100 \mathrm{mM}$ leptin treatment compared with $\mathrm{C}$ cells $(\mathrm{P}<0.05)$. However, leptin treatment had no significant effect on $\beta$-catenin expression in the normal human breast cell line Hs 578Bst (data not shown). These results suggest that leptin may promote the growth of breast cancer by activating the $\mathrm{Wnt} / \beta$-catenin pathway.
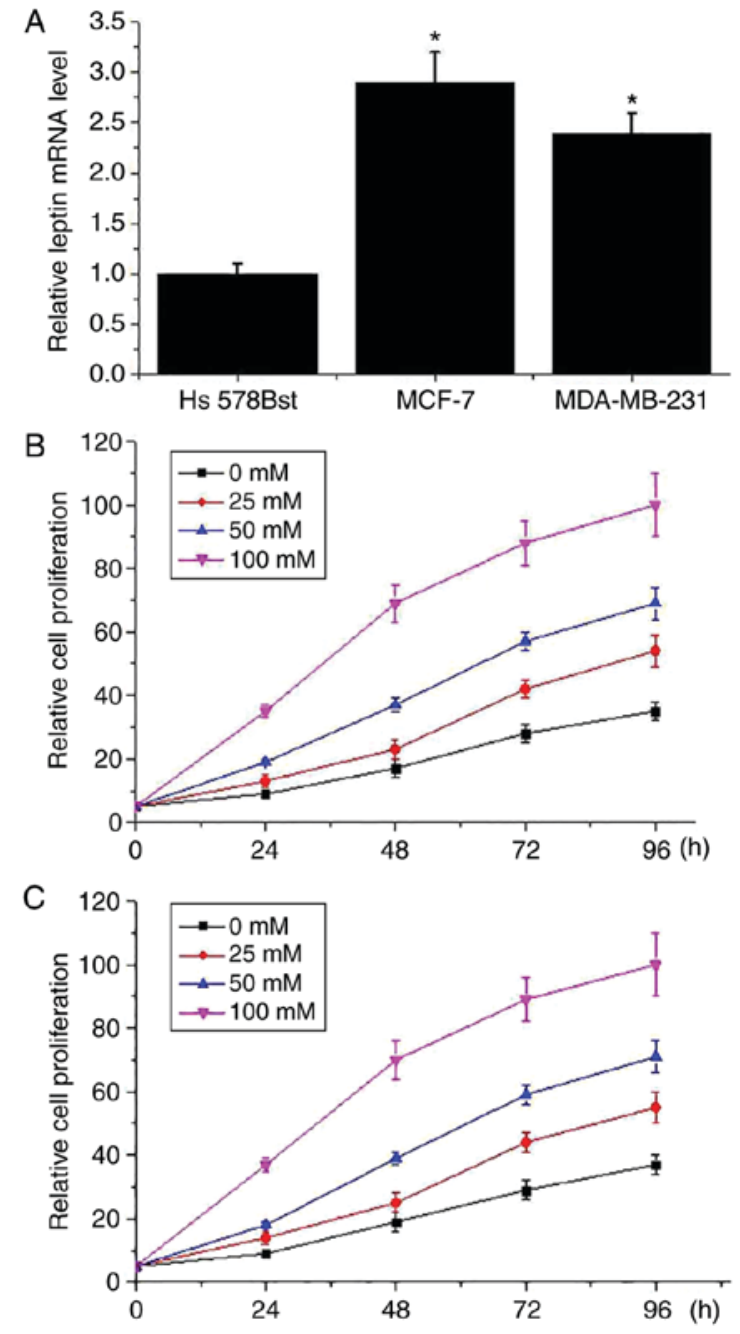

Figure 3. Effect of leptin treatment on cell proliferation of breast cancer. (A) Relative expression level of leptin mRNA in the normal human breast cell line Hs 578Bst, and breast cancer cell lines MCF-7 and MDA-MB-231. (B) Leptin treatment on cell proliferation of breast cancer cell line MCF-7. (C) Leptin treatment on cell proliferation of breast cancer cell line MDA-MB-231. ${ }^{*} \mathrm{P}<0.05$ vs. Hs $578 \mathrm{Bst}$.

Wnt pathway inhibitor inhibited the enhancing effects of leptin on proliferation of breast cancer. Wnt inhibitor PNU-74654 was used to treat breast cancer cells in culture with $100 \mathrm{mM}$ 


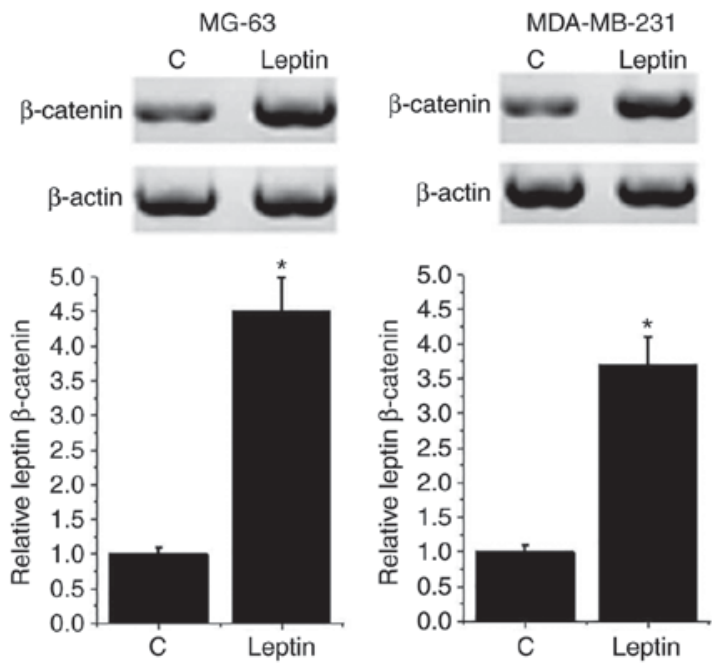

Figure 4. Effect of leptin treatment on $\beta$-catenin expression in breast cancer cells. ${ }^{*} \mathrm{P}<0.05$ vs. control cells. $\mathrm{C}$, control.

leptin and culture medium. As presented in Fig. 5, $100 \mathrm{mM}$ leptin markedly promoted the proliferation of both breast cancer cell lines. However, Wnt inhibitor markedly ameliorated this effect in both breast cancer lines.

\section{Discussion}

Leptin is a type of hormone that can be transported within the human body to participate in a variety of physiological and biochemical processes. In contrast with the function of ghrelin as a 'hunger hormone', leptin is a 'satiety hormone' that inhibits feelings of hunger to regulate energy balance (15). Previous studies have demonstrated that the increased expression level of leptin is usually accompanied with the development of various human diseases, including cardiovascular disease and non-alcoholic fatty liver disease $(8,9)$. Leptin expression was significantly upregulated in esophageal cancer, and increased expression level of leptin predicts poor prognosis (16). Besides the direct roles of leptin in pathological processes, increased expression level of leptin in tumor tissue is also responsible for the development of drug resistance in the treatment of certain types of human cancer, such as gastro-esophageal adenocarcinomas (17). Treatment of breast cancer is also challenged by drug resistance $(18,19)$. In the present study, the expression level of leptin mRNA was significantly higher in tumor tissues than in adjacent healthy tissues of 43 out of 48 patients with breast cancer. In addition, serum level of leptin protein was also significantly higher in patients with breast cancer than in normal controls. A previous study has demonstrated that leptin is highly expressed in breast cancer tissues with drug resistance (20). Those data suggest that increased leptin expression may be associated with the development of breast cancer, and leptin may also serve as a target to improve treatment outcomes of breast cancer by reducing chemotherapy resistance.

Leptin promotes proliferation of both normal tissue cells and cancer cells. In a previous study of prostate cancer, Somasundar et al (21) reported that increased expression of leptin was closely correlated with the increased proliferation ability of cancer cells, and downregulation of leptin expression
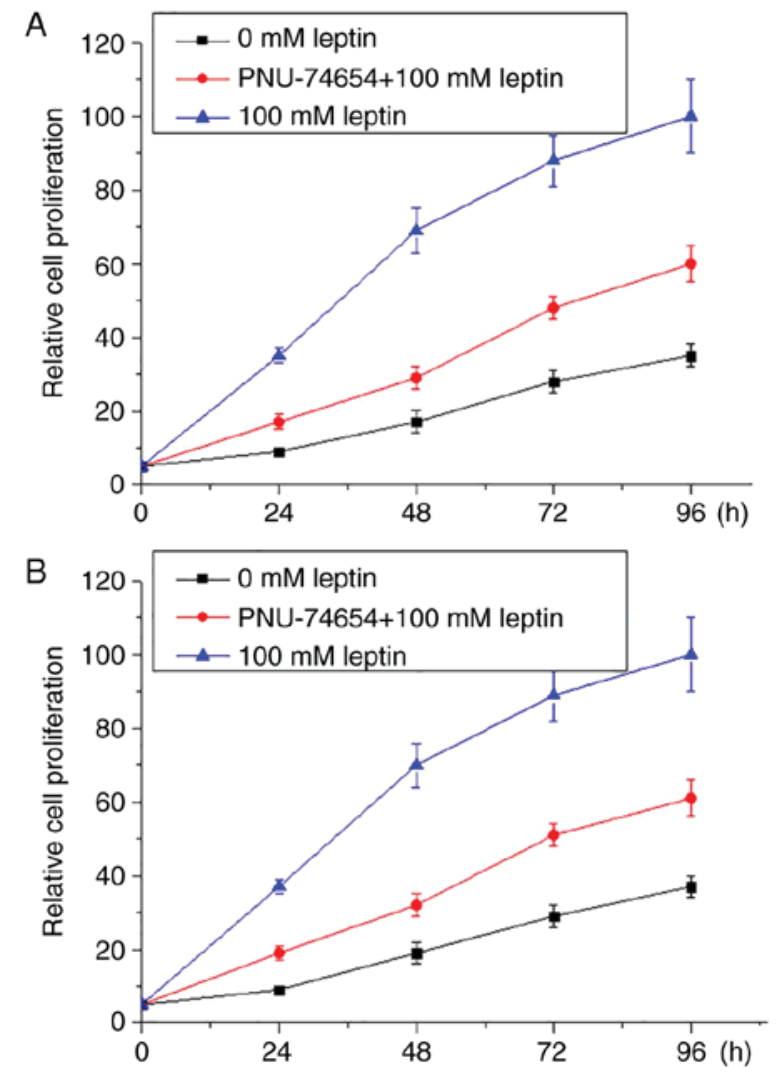

Figure 5. Effect of Wnt inhibitor on proliferation of breast cancer cells cultured with the $100 \mathrm{mM}$ leptin and culture medium. (A) Effect of Wnt inhibitor on proliferation of breast cancer cell line MCF-7. (B) Effect of Wnt inhibitor on proliferation of breast cancer cell line MDA-MB-231.

significantly reduced the proliferation rate of prostate cancer cells, indicating that leptin may serve as a potential target for the treatment of prostate cancer. In another study, Wang et al (22) reported that increased expression of leptin promoted cell proliferation and inhibited cell apoptosis of colorectal carcinoma, which in turn accelerated tumor growth. In the present study, leptin increased the proliferation rate of two breast cancer cell lines in a dose-dependent manner, indicating that leptin promotes the growth of breast cancer by stimulating cancer cell proliferation.

$\mathrm{Wnt} / \beta$-catenin is a key player in the development of various types of cancer. In a previous study of lung cancer, Teng et al (23) reported that Wnt/ $\beta$-catenin signal transduction served pivotal roles in regulating the proliferation and differentiation of cancer stem cells. Activation of the Wnt/ $\beta$-catenin pathway is enriched in different types of breast cancers, and increased expression level of $\beta$-catenin typically indicates poor treatment outcomes (24); therefore, the Wnt/ $\beta$-catenin pathway is considered to be a potential target for the treatment of breast cancer (25). In the present study, treatment with $100 \mathrm{mM}$ leptin significantly increased the expression level of $\beta$-catenin in breast cancer cell lines MCF-7 and MDA-MB-231, indicating that leptin can activate the $\mathrm{Wnt} / \beta$-catenin pathway in breast cancer. In addition, treatment with leptin inhibitor markedly reduced the enhancing effects of leptin on the proliferation of breast cancer cells. Those data suggest that leptin can promote the proliferation of breast cancer cells at least partially by activating the $\mathrm{Wnt} / \beta$-catenin pathway. 
In conclusion, leptin expression level was increased in breast cancer tissues compared with adjacent healthy tissues. Serum level of leptin protein was significantly higher in patients with breast cancer than in normal controls. Leptin promoted the proliferation of breast cancer cells and activated the $\mathrm{Wnt} / \beta$-catenin pathway, whereas treatment with leptin inhibitor markedly reduced the enhancing effects of leptin on the proliferation of breast cancer cells. These findings suggest that leptin can promote breast cancer growth by activating the Wnt/ $\beta$-catenin pathway. However, the present study was also limited by some shortcomings; for example, nuclear translocation of $\beta$-catenin in breast cancer cells was not confirmed by immunocytochemistry. The present authors intend to present this data in a future study. In addition, leptin gene knockdown and overexpression breast cancer cell lines will also be established to further confirm the conclusions of the present study.

\section{Acknowledgements}

Not applicable.

\section{Funding}

No funding was received.

\section{Availability of data and materials}

The datasets used and/or analyzed during the present study are available from the corresponding author on reasonable request.

\section{Authors' contributions}

XL and LeZ designed the present study; XL, SW and LiZ performed experiments; XL, HZ and LZ analyzed the data; and LeZ wrote the manuscript. All authors read and approved the manuscript.

\section{Ethics approval and consent to participate}

The present study was approved by the Ethics Committee of China-Japan Union Hospital (Changchun, China), and all patients provided written informed consent.

\section{Consent for publication}

All patients provided written informed consent.

\section{Competing interests}

The authors declare that they have no competing interests.

\section{References}

1. Holohan C, Van Schaeybroeck S, Longley DB and Johnston PG: Cancer drug resistance: An evolving paradigm. Nat Rev Cancer 13: 714-726, 2013.

2. Housman G, Byler S, Heerboth S, Lapinska K, Longacre M, Snyder N and Sarkar S: Drug resistance in cancer: An overview. Cancers (Basel) 6: 1769-1792,2014.

3. Longley DB and Johnston PG: Molecular mechanisms of drug resistance. J Pathol 205: 275-292, 2005.
4. O'Driscoll L and Clynes M: Biomarkers and multiple drug resistance in breast cancer. Curr Cancer Drug Targets 6: 365-384, 2006.

5. Ellis LM and Hicklin DJ: Resistance to targeted therapies: Refining anticancer therapy in the era of molecular oncology. Clin Cancer Res 15: 7471-7478, 2009.

6. Sorrentino A, Liu CG, Addario A, Peschle C, Scambi G and Ferlini C: Role of microRNAs in drug resistant ovarian cancer cells. Gynecol Oncol 111: 478-486, 2008.

7. Pan $\mathrm{H}$, Guo J and Su Z: Advances in understanding the interrelations between leptin resistance and obesity. Physiol Behav 130: 157-169, 2014

8. Wallace AM, McMahon AD, Packard CJ, Kelly A, Shepherd J, Gaw A and Sattar N: Plasma leptin and the risk of cardiovascular disease in the west of Scotland coronary prevention study (WOSCOPS). Circulation 104: 3052-3056, 2001.

9. Polyzos SA, Aronis KN, Kountouras J, Raptis DD, Vasiloglou MF and Mantzoros CS: Circulating leptin in non-alcoholic fatty liver disease: A systematic review and meta-analysis. Diabetologia 59: 30-43, 2016

10. Stolzenberg-Solomon RZ, Newton CC, Silverman DT, Pollak M, Nogueira LM, Weinstein SJ, Albanes D, Männistö S and Jacobs EJ: Circulating leptin and risk of pancreatic cancer: A pooled analysis from 3 cohorts. Am J Epidemiol 182: 187-197, 2015.

11. Andò S, Barone I, Giordano C, Bonofiglio D and Catalano S: The multifaceted mechanism of leptin signaling within tumor microenvironment in driving breast cancer growth and progression. Front Oncol 4: 340, 2014.

12. Livak KJ and Schmittgen TD: Analysis of relative gene expression data using real-time quantitative PCR and the 2(-Delta Delta C(T)) method. Methods 25: 402-408, 2001.

13. Nagaraj AB, Joseph P, Kovalenko O, Singh S, Armstrong A, Redline R, Resnick K, Zanotti K, Waggoner S and DiFeo A: Critical role of Wnt/ $\beta$-catenin signaling in driving epithelial ovarian cancer platinum resistance. Oncotarget 6: 23720-23734, 2015.

14. Huang G, Zhu H, Shi Y, Wu W, Cai H and Chen X: cir-ITCH plays an inhibitory role in colorectal cancer by regulating the Wnt/ $\beta$-catenin pathway. PLoS One 10: e0131225, 2015.

15. Friedman JM and Halaas JL: Leptin and the regulation of body weight in mammals. Nature 395: 763-770, 1998.

16. Howard JM, Cathcart MC, Healy L, Beddy P, Muldoon C, Pidgeon GP and Reynolds JV: Leptin and adiponectin receptor expression in oesophageal cancer. Br J Surg 101: 643-652, 2014.

17. Bain GH, Collie-Duguid E, Murray GI, Gilbert FJ, Denison A, McKiddie F, Ahearn T, Fleming I, Leeds J, Phull P, et al: Tumour expression of leptin is associated with chemotherapy resistance and therapy-independent prognosis in gastro-oesophageal adenocarcinomas. Br J Cancer 110: 1525-1534, 2014.

18. Park HY, Kwon HM, Lim HJ, Hong BK, Lee JY, Park BE, Jang Y, Cho SY and Kim HS: Potential role of leptin in angiogenesis: Leptin induces endothelial cell proliferation and expression of matrix metalloproteinases in vivo and in vitro. Exp Mol Med 33: 95-102, 2001.

19. Ding Y, Cao Y, Wang B, Wang L, Zhang Y, Zhang D, Chen X, Li M and Wang C: APPL1-mediating leptin signaling contributes to proliferation and migration of cancer cells. PLoS One 11: e0166172, 2016.

20. McGlothen TZ, Hogan-Blaylock D, Gillespie C, Colbert L, Guo G, Sanford G and Gonzalez-Perez RR: Leptin-Notch-Wnt axis affects drug resistance in breast cancer. Cancer Res: 72, 2012.

21. Somasundar P, Frankenberry KA, Skinner H, Vedula G, McFadden DW, Riggs D, Jackson B, Vangilder R, Hileman SM and Vona-Davis LC: Prostate cancer cell proliferation is influenced by leptin. J Surg Res 118: 71-82, 2004.

22. Wang D, Chen J, Chen H, Duan Z, Xu Q, Wei M, Wang L and Zhong M: Leptin regulates proliferation and apoptosis of colorectal carcinoma through PI3K/Akt/mTOR signalling pathway. J Biosci 37: 91-101, 2012.

23. Teng Y, Wang X, Wang Y and Ma D: Wnt/beta-catenin signaling regulates cancer stem cells in lung cancer A549 cells. Biochem Biophys Res Commun 392: 373-379, 2010.

24. Khramtsov AI, Khramtsova GF, Tretiakova M, Huo D, Olopade OI and Goss KH: Wnt/beta-catenin pathway activation is enriched in basal-like breast cancers and predicts poor outcome. Am J Pathol 176: 2911-2920, 2010

25 . King TD, Suto MJ and Li Y: The Wnt/ $\beta$-catenin signaling pathway: A potential therapeutic target in the treatment of triple negative breast cancer. J Cell Biochem 113: 13-18, 2012.

This work is licensed under a Creative Commons Attribution-NonCommercial-NoDerivatives 4.0 International (CC BY-NC-ND 4.0) License. 